\title{
Sistema Web Para Apoio ao Ensino da Pronúncia do Idioma Inglês Americano
}

\author{
José F. Pereira $^{1}$, Matheus E. Franco ${ }^{1}$, Caroline F. C. Santos ${ }^{1}$ \\ ${ }^{1}$ Departamento de Computação - IFSULDEMINAS- Campus Machado \\ CEP - 37.750-000 - MG - Brasil \\ felipe7seven@gmail.com, matheus.franco@ifsuldeminas.edu.br, \\ caroline.santos@ifsuldeminas.edu.br
}

\begin{abstract}
The teaching of the English language is relevant, and the use of information and communication technologies in this process is important. Thus, this article describes the implementation and evaluation of a web system to support the teaching process of English language learning. The results indicate that the developed web system is promising in view of the positive evaluation by students and teachers of the area.
\end{abstract}

Resumo. O ensino da língua inglesa é grande relevância, sendo que a utilização das tecnologias da informação e comunicação neste processo é importante. Assim, este artigo descreve a implementação e avaliação de um sistema web para apoio ao processo de ensino aprendizagem da pronúncia a língua inglesa. Os resultados indicam que o sistema web desenvolvido é promissor tendo em vista a avaliação positiva por parte de estudantes $e$ professores da área.

\section{Introdução}

O idioma inglês é uma língua global com considerável presença nos ambientes acadêmicos, sendo notória sua utilização em publicações científicas e livros [Broughton et al. 2002], sendo recentemente utilizado também em cursos abertos online e massivos (MOOC).

A utilização da tecnologia para apoiar as atividades de ensino-aprendizagem de idiomas possui considerável relevância diante de diferentes propostas tecnológicas que surgem a cada momento em um mundo que se vê na era do conhecimento e da tecnologia [Martins and Moreira 2012].

Segundo Lim e colaboradores [Lim et al. 2010], o Ensino de Idiomas Assistido por Computador ou Computer Assisted Language Learning (CALL) têm sido objeto de estudo para muitos pesquisadores, onde os resultados obtidos indicam que esses materiais didáticos digitais são geralmente efetivos em ajudar os estudantes a aprender, melhorando, assim, o processo de aprendizagem.

A aplicação de tecnologia multimídia no processo ensino-aprendizagem de uma língua estrangeira cria um ambiente propicio para implementar o ensino de qualidade de línguas estrangeiras, contribuindo para melhorar as capacidades de língua inglesa dos estudantes em diferentes os modos [Chen and Liu 2012]. Ainda segundo Chen e Liu a internet e tecnologia multimídia proveem meios de ensino aprendizagem de língua 
estrangeira tanto para os professores quanto para os aprendizes, estes meios fazem com que o processo seja mais flexível, conveniente, interessante e eficiente.

O aprendizado de línguas assistido por computador se faz em um cenário caracterizado pela possibilidade de um aprendizado independente e de um ritmo autogestivo. Esse tipo de aprendizado pode ser efetivo devido ao imediato feedback que pode ser oferecido ao usuário. Diante do pressuposto que devem ser oferecidas aos estudantes oportunidades de praticar a língua que se está aprendendo, a tecnologia tem potencial para prover aos estudantes a oportunidade de se comunicar com outros, e praticar o idioma em estudo [Pim 2013].

Neste contexto, a pronúncia da língua inglesa pode ser uma dificuldade para aqueles que iniciam seu aprendizado [Alves and Silva Jr 2015], assim, diante de tal observação, este trabalho teve como objetivo implementar uma aplicação web para apoio ao processo ensino-aprendizagem da pronúncia do Inglês Americano.

Como recurso com para apoiar o ensino aprendizagem de idiomas, foi utilizado o Alfabeto Fonético Internacional ou IPA (International Phonetic Alphabet), pois ele apresenta notações fonéticas que representam cada som produzido por qualquer idioma, e o aprendizado do mesmo pode contribuir no aprendizado do idioma Inglês [Skandera and Burleigh 2005], haja vista que as transliterações fonéticas utilizadas em muitos dicionários e livros de ensino do inglês fazem uso do IPA.

\section{Metodologia}

Através de levantamentos com três professores da disciplina de inglês de nossa instituição por questionários estruturados, observaram-se limitações no ensino do tópico de pronúncia utilizando a abordagem tradicional expositiva, sendo este por vezes não apresentado no conteúdo programático.

Para o desenvolvimento da aplicação foi utilizada a tecnologia ASP.NET MVC 5 na linguagem C\# além outras tecnologias como HTML, CSS, JavaScript e AJAX. Não foi utilizado um banco de dados relacional, para armazenamento dos dados foi utilizado arquivos JSON. Para que o sistema web fosse responsivo foi utilizado o framework Bootstrap. O desenvolvimento da aplicação web foi realizado utilizando conteúdos sobre pronúncia do idioma inglês, sendo a aplicação principal um quadro fonêmico que apresenta o IPA (International Phonetic Alphabet) para a língua inglesa.

Como última etapa do presente trabalho, a aplicação web foi avaliada por 32 (trinta e dois) alunos e quatro professores. Os questionários utilizados com alunos e professores estão disponíveis para acesso através da url https://goo.gl/fiaZ8J.

\section{Resultados e Discussões}

A aplicação web desenvolvida está disponível de forma aberta através da url https://goo.gl/KjsAvW. A figura 1 apresenta o conteúdo principal do sistema, um quadro fonêmico que contém símbolos que representam os sons da língua inglesa. Ao clicar sobre um símbolo é apresentado um quadro com os detalhes do mesmo. 
VI Congresso Brasileiro de Informática na Educação (CBIE 2017)

Anais do XXIII Workshop de Informática na Escola (WIE 2017)

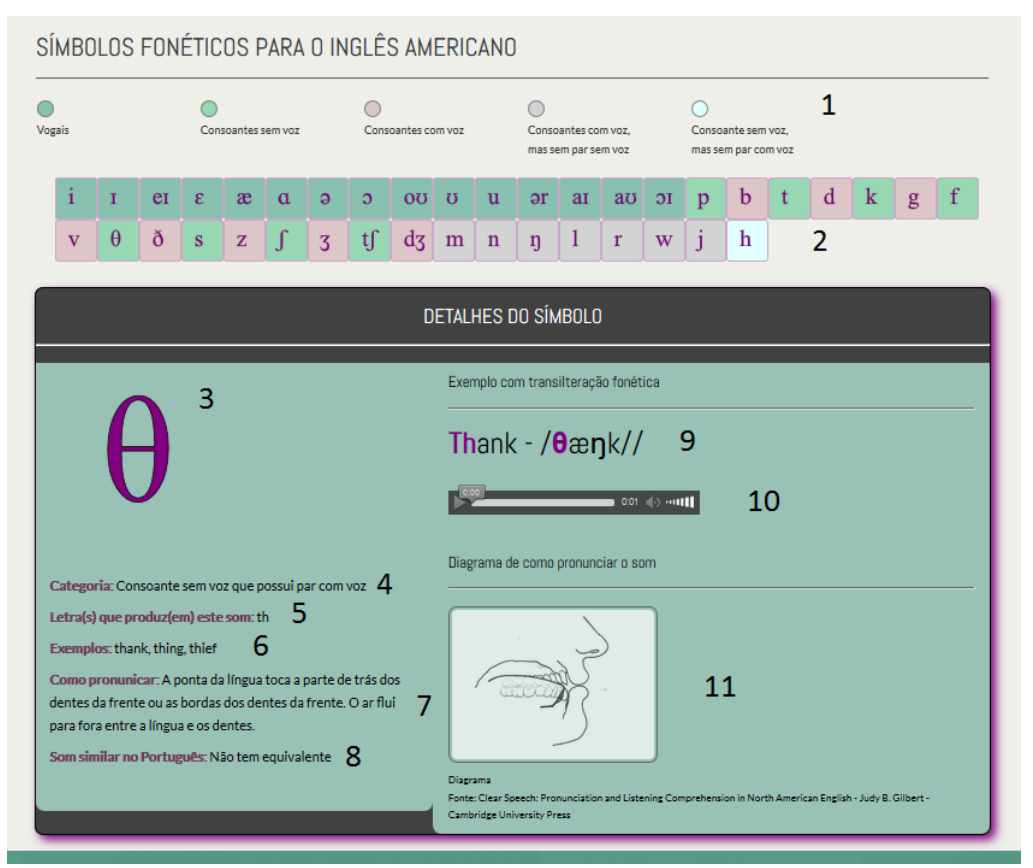

Figura 1. Quadro fonêmico interativo

A aplicação foi avaliada por 32 alunos de nível superior, de acordo com os dados obtidos e apresentados na figura $12,56,3 \%$ dos alunos avaliaram como excelente o design (aparência, disposição dos elementos e de cores) da aplicação, 34,4\% avaliaram com muito bom e $9,4 \%$ bom. $\mathrm{Na}$ avaliação do conteúdo principal, o quadro fonêmico, $59,4 \%$ dos alunos avaliadores o caracterizaram como excelente, $34,4 \%$ muito bom e 6,3\% bom. Para a compreensibilidade da aplicação, 53,1\% dos alunos disseram ser excelente, 43,8\% muito bom e 3,1\% bom. Em relação ao nível de confiança das informações que o sistema transmite, 59,4\% apontaram como excelente, $21,9 \%$ muito bom e $18,8 \%$ bom.

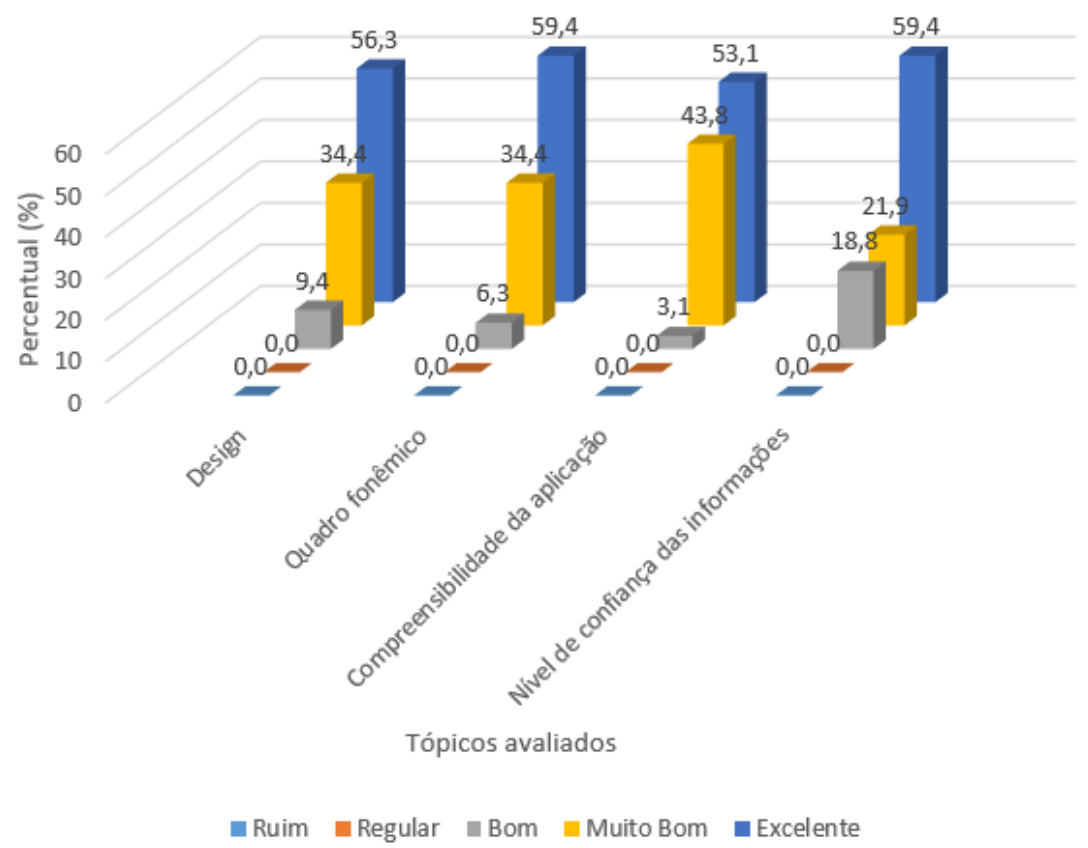

Figura 2. Tópicos avaliados 
É importante salientar que, os resultados demonstraram que apenas três dos 32 alunos já conheciam o IPA, o que justifica o desenvolvimento de objetos de aprendizagem para difundir o conhecimento acerca deste tópico.

Além disto, quarto professores de inglês avaliaram a potencialidade da aplicação web desenvolvida como objeto de aprendizagem. De acordo com os dados obtidos, $25 \%$ dos professores atribuíram nota excelente à didática e $75 \%$ classificaram-na como muito boa. Em relação ao nível de precisão das informações apresentadas, $75 \%$ dos professores afirmaram que a precisão das informações é excelente e $25 \%$ afirmaram que ela é muito boa.

\section{Conclusão}

O desenvolvimento da aplicação web para o apoio o ensino-aprendizagem de pronúncia da língua inglesa foi concluído satisfatoriamente, contudo aperfeiçoamentos ainda serão realizados. Os resultados indicaram que o uso de um sistema web para apoio ao ensino da pronúncia fazendo uso do IPA como recurso principal pode colaborar para o ensinoaprendizagem de pronúncia do idioma inglês, desde que inserido em um contexto pedagógico previamente definido. Isto corrobora com autores mencionados neste trabalho os quais afirmaram que o uso de tecnologia web no ensino-aprendizagem de línguas pode contribuir tanto para o professor quanto para o aluno.

\section{Agradecimentos}

Ao Instituto Federal de Educação, Ciência e Tecnologia do Sul de Minas Gerais IFSULDEMINAS e a Fundação de Amparo à Pesquisa do Estado de Minas Gerais FAPEMIG pelo apoio concedido.

\section{Referências}

Alves, A. C. and Silva Jr, L. J. (2015). A Transferência Fonológica no Ensino do Inglês Como L2. . Congresso Nacional de Educação.

Broughton, G., Brumfit, C., Pincas, A. and Wilde, R. D. (2002). Teaching English as a foreign language. Routledge.

Chen, E. C. and Liu, J. (2012). Applying multimedia technology to the teaching and learning of college English in China: problems and solutions. Journal of Information Technology and Application in Education, v. 9, p. 108-111.

Lim, T. H., Hoe, F. T. and Tan, T. G. (2010). The development and evaluation of an eworkbook for learning mandarin. In Science and Social Research (CSSR), 2010 International Conference on. . IEEE.

Martins, C. B. M. J. and Moreira, H. (2012). The field CALL (Computer Assisted Language Learning): definitions, aims and scope. Calidoscópio, v. 10, n. 3, p. 247.

Pim, C. (2013). Emerging technologies, emerging minds: digital innovations within the primary sector. Innovations in learning technologies for English language teaching. London: British Council, p. 20-42.

Skandera, P. and Burleigh, P. (2005). A manual of English phonetics and phonology: twelve lessons with an integrated course in phonetic transcription. Gunter Narr 
VI Congresso Brasileiro de Informática na Educação (CBIE 2017)

Anais do XXIII Workshop de Informática na Escola (WIE 2017)

Verlag.

Boulic, R. and Renault, O. (1991) “3D Hierarchies for Animation”, In: New Trends in Animation and Visualization, Edited by Nadia Magnenat-Thalmann and Daniel Thalmann, John Wiley \& Sons ltd., England. 